\title{
Prevalence of Elder Abuse and Neglect: Findings from First Macedonian Study
}

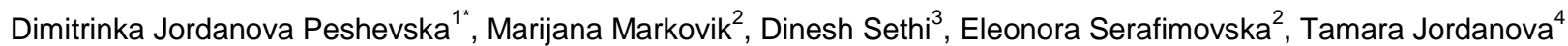 \\ ${ }^{1}$ World Health Organization, Country Office Skopje, Republic of Macedonia; ${ }^{2}$ Institute for Sociological, Political and Juridical \\ Research, Ss Cyril and Methodius University of Skopje, Skopje, Republic of Macedonia; ${ }^{3}$ World Health Organization, \\ Regional Office for Europe, Copenhagen, Denmark; ${ }^{4}$ National Association for Improvement of the Health and Rights of \\ Persons with Mental IIInesses and Other Vulnerable Group, Skopje, Republic of Macedonia
}

Citation: Jordanova Peshevska D, Markovik M, Sethi D, Serafimovska E, Jordanova T. Prevalence of Elder Abuse and Neglect: Findings from First Macedonian Study. OA Maced J Med Sci. 2014 Jun 15; 2(2):353-359. http://dx.doi.org/10.3889/oamjms.2014.061

Key words: Psychological abuse; financial abuse; physical abuse; physical injuries; sexual abuse; neglect.

Correspondence: Dimitrinka Jordanova Peshevska, MSc. World Health Organization, Country Office Skopje, "Drezdenska 22", 1000 Skopje, Republic of Macedonia. Tel: 3063 710; Fax: 38923063710 . E-mail jpd@euro.who.int

Received: 28-Mar-2014; Revised: 06-May2014; Accepted: 07-May-2014; Online first: 26-May-2014

Copyright: ( 2014 Jordanova Peshevska et al. This is an open access article distributed under the terms of the Creative Commons Attribution License, which permits unrestricted use, distribution, and reproduction in any medium, provided the original author and source are credited.

Competing Interests: The authors have declared that no competing interests exist.

\section{Abstract}

OBJECTIVES: One of the study objectives was to explore the prevalence of elder abuse and neglect in the country.

METHOD: Total of 960 respondents aged 65 years and above (44.7\% of male and $55.3 \%$ ) in private households, from all eight statistical regions participated in the study. Respondents were sampled through three staged national representative sampling procedure. Data were collected using a cognitively validated questionnaire for investigating elder abuse and neglect (psychological abuse, physical abuse, physical injury; financial abuse; sexual abuse and neglect) and Geriatric Depression Scale. The MMSE test was used as a pre-selection method. Statistical significance was set up at $p<0.05$

RESULTS: Three hundred seven (32.0\%) respondents reported experience of any type of abuse and neglect. A single form of abuse was reported by $56.4 \%$ of participants, and two types of abuse by $27.4 \%$ of participants reporting abuse. Data showed that psychological abuse was the most prevalent form of abuse $(25.7 \%)$, followed by financial abuse $(12.0 \%)$, physical abuse $(5.7 \%)$, physical injury $(3.1 \%)$ and sexual abuse, and reported only by females $(1.3 \%)$. Some type of neglect was reported by $6.5 \%$ of respondents.

CONCLUSIONS: Defining the phenomenon of elder abuse and neglect in the context of our country can facilitate support of abused older people and, most importantly, may help develop policy and programmes based on evidence-based practices, targeting prevention and response.

\section{Introduction}

Maltreatment of older people, termed 'elder abuse', was first described in British scientific journals in 1975 [1]. Later, in the 1980s in some countries, scientific research and government action emerged. In 1996, the Forty-Ninth World Health Assembly (WHA) adopted Resolution WHA49.25 [2], declaring violence a major and growing public health problem across the world. For a long time the phenomenon of elder abuse was seen as a social and criminal justice problem, but following the 2002 World health report, it has been clearly identified as a public health problem [3]. With WHA Resolution $56.24[3,4]$, violence was put on the international agenda as a leading worldwide public health problem. The WHA drew attention to the serious consequences of violence - both in the short term and the long term - for individuals, families, communities and countries, and stressed the damaging effects of violence on health care services.

Life expectancy in developed countries is increasing, the world's elderly population - people 60 years of age and older - is 650 million. By 2050, this older population is forecast to reach 2 billion $[5,6]$. There are many terms used to describe old age. In this study the terms 'elderly' or 'older people' are used and refer to people aged 65 years and older [6, 7]. According to the definition for elderly people given by $\mathrm{WHO}$, the critical age for classification as old is 65 years $[6,7]$. This definition is not universal, however. Most developed countries accept the chronological 
age of 65 years and over as a definition of elderly, but in some parts of the developing world, for example, this is not the case $[6,7]$.

One commonly used definition of elder abuse is that adopted by WHO and INPEA: "Elder abuse is a single or repeated act, or lack of appropriate action, occurring within any relationship where there is an expectation of trust, which causes harm or distress to an older person" [8]. According to WHO, it can take the various forms of physical, psychological, emotional, sexual and financial abuse. It can also result from intentional or unintentional neglect $[3,5]$.

\section{Types of elder abuse}

In the different studies and literature $[3,6,9]$ the following types of elder abuse have been identified:

Physical abuse. This includes violent actions which can cause physical pain or injuries to the older person.

Psychological/emotional abuse. This category refers to actions which can cause mental pain or distress through verbal or nonverbal acts.

Financial/material abuse. This type of abuse refers to all actions of financial duress or illegal use of an older person's property, money or other type of material private property.

Sexual abuse. This refers to sexual activity without the consent of the older person. Sexual abuse can also be described as the intention to control the older person sexually.

Neglect. Neglect can be passive or active. Passive neglect refers to unintentional failure to provide necessary care for an older person. Active neglect refers to intentional failure to provide basic necessary elements of care (cleaning, cooking, medication and nutrition or other everyday activities important for a person's normal life), [3, 6, 9].

In the country a systematic scientific approach to elder maltreatment has been lacking until recently. National report on violence and health have in 2006, highlighted elder abuse as a national public health concern [10]. However, the only data on elder maltreatment are based on reports of agencies working in the area of domestic violence [11].

This paper has focused on exploring the phenomena on elderly maltreatment with particular focus on prevalence of different types of abuse and neglect.

The data used in this article is an integral part of the data collected for more comprehensive project "A Community survey in Macedonia of the prevalence of elderly abuse". The study has been conducted during the period from December 2011 to February 2012. Implementation of the study was enabled with technical and financial support by the World Health Organization in collaboration with the Institute of Sociological, Political and Juridical Research in Skopje.

\section{Method}

The study is a community based household survey at national level, involved administering a faceto-face questionnaire. Total of 960 respondents aged 65 years and above in private households, from all eight statistical regions in the country participated in the study, which represents $0.4 \%$ of the total number of people 65 years of age and above. Sampling was carried out by quota stratified sampling. The first step was selection of potential participants by strata, based on criteria of gender, ethnicity, residence (city/village), and municipality (percentage of respondents from each municipality correspond to its contribution to the total population). The quota of respondents in each strata depended on population distribution [12].

\section{Measures}

The questionnaire used in the Macedonian survey mostly follow the methodology of the: ABUEL survey - Abuse of Elderly in Europe, a multinational prevalence survey, conducted in Germany, Greece, Italy, Lithuania, Portugal, Spain, Sweden, [13] and AVOW- Prevalence study of abuse and violence against older women, a multicultural survey conducted in Austria, Belgium, Finland, Lithuania and Portugal, [14]. The questionnaire enclosed questions on: sociodemographic data; healthy life styles data (smoking, alcohol use, diet); physical and mental health, and exposure to abuse/neglect (psychological abuse, physical abuse, physical injury; financial abuse; sexual abuse and neglect). Statistical significance was set up at $p<0.05$. The final version of the questionnaire was available both in Macedonian and Albanian language. A qualitative analysis of the Final Questionnaire Form has been undertaken by a Focus group of experts and the Scientific Committee of the study. The ethics committee at the University "St. Kiril and Metodij" granted ethical approval to the study. The inclusion criterion for involvement to participation in the study was absence of mental impairment (such as dementia), where participants were screened using questions from the Mini-Mental State Examination (MMSE) [15].

\section{Results}

In the study sample, men (44.7\%) and women (55.3\%) are almost identical to the planned percentages as per population age distribution. The vast majority of the respondents are in the age group 65-69 years $(32.1 \%)$, while the least group was aged over 85 years (4.3\%). Regarding distribution of the 
respondents by ethnicity, Macedonians are $76.4 \%$, followed by Albanians (16.0\%) and other groups as per country population distribution (see Table 1).

The country has eight statistical regions and the respondents are distributed with regards to the regions as per country population distribution. The highest percentage of respondents had only completed primary school (26.8\%), and the lowest percentage of respondents held higher degrees $(0.6 \%)$ as presented in Table 1 . The highest percentages of the respondents are in the groups of married/cohabitation (56.7\%) and widow (37.7). Older people living alone represent up to $15.8 \%$ of the sample, while the highest percentage of respondents are living in households with more than four family members is $39.3 \%$. The percentage of respondents living with a partner $56.7 \%$ is little bit higher than that for participants without a partner 43.3 (Table 1). The highest percentage of participants had an average number of facilities $(63.7 \%)$. The highest percentage of participants answered that total household income partially satisfied their needs $(49.6 \%)$.

Table 1: Characteristics of the sample $(\mathrm{N}=960)$.

\begin{tabular}{|c|c|}
\hline Gender & Total\% \\
\hline Male & 44.7 \\
\hline Female & 55.3 \\
\hline Age & Total \% \\
\hline $65-69$ & 32.0 \\
\hline $70-74$ & 28.9 \\
\hline $75-79$ & 22.1 \\
\hline $80-84$ & 12.7 \\
\hline Over 85 & 4.3 \\
\hline Ethnicity & Total \% \\
\hline Macedonian & 76.4 \\
\hline Albanian & 16.0 \\
\hline Roma & 1.9 \\
\hline Serb & 1.1 \\
\hline Vlach & 0.5 \\
\hline Turkish & 2.1 \\
\hline Bosnian & 1.0 \\
\hline Other & 1.0 \\
\hline Level of education & Total \% \\
\hline No education & 10.4 \\
\hline Did not complete primary school & 25.8 \\
\hline Primary school education & 26.8 \\
\hline Secondary education & 25.2 \\
\hline University/other higher education & 11.2 \\
\hline Specialist, MA, PhD & 0.6 \\
\hline Marital status & Total \% \\
\hline Single (never married) & 3.6 \\
\hline Married/civil partnership) & 56.7 \\
\hline Divorced & 2.0 \\
\hline Widowed & 37.7 \\
\hline Occupational status & Total \% \\
\hline Fully retired & 87.5 \\
\hline Full-time employed & 0.6 \\
\hline Part-time employed & 0.4 \\
\hline Unemployed & 11.5 \\
\hline Personal income in euro & Total \% \\
\hline Up to 80 & 7.4 \\
\hline $81-146$ & 40.8 \\
\hline $147-226$ & 27.5 \\
\hline $227-307$ & 10.8 \\
\hline $308-388$ & 3.4 \\
\hline $389-467$ & 1.3 \\
\hline$<468$ & 0.9 \\
\hline No income & 7.9 \\
\hline Region & Total\% \\
\hline Pelagonija & 13.5 \\
\hline Vardar & 8.0 \\
\hline North-eastern & 7.4 \\
\hline South-western & 9.8 \\
\hline Skopje & 30.2 \\
\hline South-eastern & 9.1 \\
\hline Polog & 10.8 \\
\hline Eastern & 11.2 \\
\hline
\end{tabular}

\section{Overall prevalence rates of elder maltreatment}

Table 2 shows the overall distribution of all types of abuse/neglect. The number of participants who reported occurrence of any type of abuse and neglect was $307(32.0 \%)$. The number of participants who did not experience any type of maltreatment was $653(68.0 \%)$ as presented in Table 2.

Table 2: Overall prevalence rates of abuse/neglect $(\mathrm{N}=960)$.

\begin{tabular}{lccc}
\hline Prevalence of abuse/neglect & Total $(\%)$ & Male (\%) & Female (\%) \\
\hline No abuse/neglect & 68.0 & 32.1 & 35.9 \\
Abused & 32.0 & 12.6 & 19.4 \\
Total & 100.0 & 44.7 & 55.3 \\
\hline
\end{tabular}

Regarding the experience of different types of abuse and neglect, psychological abuse was the most frequent reported (25.7\%), followed by financial abuse $(12.0 \%)$, physical abuse (5.7\%), physical injury $(3.1 \%)$ and sexual abuse reported only in women (1.3\%).

Table 3: Prevalence of different types of abuse/neglect.

\begin{tabular}{lccc}
\hline Type of abuse $(\mathrm{N}=960)$ & Total \% & Male \% & Female \% \\
\hline Psychological abuse & 25.7 & 9.5 & 16.2 \\
Physical abuse & 5.7 & 1.7 & 4.0 \\
Physical injury & 3.1 & 0.8 & 2.3 \\
Financial abuse & 12.0 & 5.5 & 6.5 \\
Sexual abuse & 1.3 & 0 & 1.3 \\
Neglect & 6.6 & 1.9 & 4.7 \\
\hline
\end{tabular}

Table 4 presents the results for the level of prevalence of multiple types of abuse, amongst all participants. The majority of the participants have experienced single form of abuse (18\%) from which $10.2 \%$ in female and $7.8 \%$ in male. Two types of abuse are experienced in $8.8 \%$ of the respondents.

Table 4: Prevalence of multiple types of abuse/neglect amongst all participants.

\begin{tabular}{lccc}
\hline Number of types of abuse/neglect & Total \% & Male $\%$ & Female $\%$ \\
\hline 1 type & 18.0 & 7.8 & 10.2 \\
2 types & 8.8 & 3.3 & 5.5 \\
t types & 3.1 & 1.3 & 1.9 \\
4 types & 1.3 & 0.3 & 0.9 \\
5 types & 0.6 & 0 & 0.6 \\
types & 0.2 & 0 & 0.2 \\
No abuse/neglect & 68.0 & 32.0 & 36.0 \\
Total $(\mathrm{N}=960)$ & 100.0 & 44.7 & 55.3 \\
\hline
\end{tabular}

\section{Types of abuse and neglect}

\section{Psychological abuse}

Data gathered from this study showed that psychological or emotional abuse was the most prevalent form of abuse (25.7\%). Psychological abuse was measured by 11 indicators. Findings for each indicator are presented in Table 5, from which it can be seen that the most frequent type of psychological abuse is insulting or swearing at (14\%), followed by shouting or yelling at $8.7 \%$.

\section{Physical abuse}

This survey included 17 indicators for physical abuse, which are listed in Table 6, from which it will be seen that overall prevalence of physical abuse was $5.7 \%$. Overall physical abuse for men was $1.7 \%$ and for women was $4.0 \%$. 
Table 5: Types of psychological abuse.

\begin{tabular}{lccc}
\hline Type of abuse & Total \% & Male \% & Female \% \\
\hline Insulted or sworn at & 14.5 & 5.1 & 9.4 \\
Threatened & 2.8 & 0.7 & 2.1 \\
Undermined or bullied & 7.2 & 2.4 & 4.8 \\
Excluded & 7.2 & 2.1 & 5.1 \\
Threatened to harm & 1.1 & 0.2 & 0.9 \\
Prevented from seeing other people & 0.7 & 0.1 & 0.6 \\
Shouted or yelled at & 8.7 & 2.9 & 5.8 \\
Did something out of spite & 3.4 & 1.1 & 2.3 \\
Called ugly names & 5.8 & 1.8 & 4.0 \\
Destroyed personal belongings & 2.3 & 0.5 & 1.8 \\
Threatened to hit or throw something at & 2.3 & 0.5 & 1.8 \\
Overall abuse* & 25.7 & 9.6 & 16.1 \\
\hline${ }^{*}$ of total number of ron
\end{tabular}

*of total number of respondents.

The most frequent types of physical abuse were pushing $(1.1 \%)$, kicking $(0.8 \%)$, grabbing $(0.8 \%)$ and slapping $(0.6 \%)$. In general, women experienced more types of physical violence, and more often than men who experienced some type of physical violence.

Table 6: Types of physical abuse.

\begin{tabular}{lccc}
\hline Type of abuse & Total \% & Male \% & Female \% \\
\hline Slapped & 0.6 & 0 & 0.6 \\
Grabbed & 0.8 & 0 & 0.8 \\
Kicked & 0.8 & 0.2 & 0.6 \\
Pushed & 1.1 & 0.1 & 1.0 \\
Burned & 0.2 & 0 & 0.2 \\
Choked & 0.2 & 0 & 0.2 \\
Having something thrown at & 0.5 & 0.2 & 0.3 \\
Twisted ankle & 0.4 & 0 & 0.4 \\
Used knife or gun & 0 & 0 & 0 \\
Punched & 0.6 & 0.2 & 0.4 \\
Slammed & 0.4 & 0 & 0.4 \\
Beaten up & 0.3 & 0 & 0.3 \\
Tied up & 0 & 0 & 0 \\
Restrained & 0 & 0 & 0 \\
Locked in room & 0 & 0 & 0 \\
Given drugs or medicine & 0 & 0 & 0 \\
Threatened with knife or gun & 0.1 & 0 & 0.1 \\
Overall physical abuse & 5.7 & 1.7 & 4.0 \\
\hline
\end{tabular}

*of total number of respondents.

\section{Physical injuries}

In this survey four types of physical injuries were used as indicators of severe physical abuse of older people, which are listed in Table 7, which gives the percentage of participants who reported experience of each type of physical injury, by gender.

Table 7: Physical injuries.

\begin{tabular}{lccc}
\hline Type of injury & Total \% & Male \% & Female \% \\
\hline Sprain, bruise, cuts & 0.9 & 0.3 & 0.6 \\
Passed out & 0.3 & 0.1 & 0.2 \\
Broken bones & 0.2 & 0 & 0.2 \\
Physical pain that still hurt next day & 0.8 & 0.2 & 0.6 \\
Other & 0.1 & 0 & 0.1 \\
Overall physical injuries $^{*}$ & 3.1 & 0.8 & 2.3 \\
\hline
\end{tabular}

*of total number of responden

The most frequent types of physical injuries were sprains, bruises and cuts from being hit (0.9). Women experienced this type of abuse more frequently than men. However, it must be pointed out that there is no significant difference between the genders in experiencing these types of injuries.

\section{Financial abuse}

Financial abuse refers to illegal use of an older person's material goods against their will. This type of abuse includes all actions where an older person's material goods are taken by force. In this survey, as indicators for financial abuse we used the eight types of financial abuse used in the AVOW study. Table 8 presents the indicators of financial abuse and the percentages of participants who reported each type of abuse, by gender.

The data in Table 8 show that the overall rate of financial abuse in older women is $6.5 \%$, in older men is $5.4 \%$ and overall is $11.9 \%$. As the data show, the most frequent types of financial abuse are trying to make the older person give money $(4.0 \%)$ making the older person hand over their money against their will $(2.8 \%)$, attempting to make the older person hand over money against their will and stealing money $(2.0 \%)$

Table 8: Financial abuse.

\begin{tabular}{lccc}
\hline Type of financial abuse & Total \% & Male \% & Female \% \\
\hline Made you hand over your money & 2.8 & 0.1 & 2.7 \\
Tried to make you give money & 4.0 & 1.2 & 2.8 \\
Tried to take or keep power against & 0.7 & 0.2 & 0.5 \\
will & 1.6 & 0.4 & 1.2 \\
Attempted to steal money & 2.0 & 0.8 & 1.2 \\
Stole money & 1.5 & 0.4 & 1.1 \\
Used fraud to take your money & 0.4 & 0.2 & 0.2 \\
Took power over you & 0.7 & 0.1 & 0.6 \\
Did something else to take your & 11.9 & 5.4 & 6.5 \\
money & & &
\end{tabular}

\section{Sexual abuse}

The study used seven indicators to identify sexual abuse among older people, which are listed in Table 9. The overall prevalence of sexual abuse is $1.35 \%$ (no male respondents reported sexual abuse). As Table 9 illustrates, the severest types of sexual abuse were the most frequent: forced women to have sexual intercourse against her will $(0.3 \%)$ and attempted sexual intercourse against the women's will $(0.3 \%)$.

Table 9: Sexual abuse.

\begin{tabular}{ll}
\hline Type of sexual abuse & Female \% \\
\hline Talked to you in a sexual way & 0.2 \\
Touched you & 0.2 \\
Tried to touch you & 0.2 \\
Made you watch pornography & 0 \\
Tried to make you watch pornography & 0 \\
Tried to have sexual intercourse against will & 0.3 \\
Forced you to have sexual intercourse against will & 0.3 \\
Other & 0 \\
Overall sexual abuse* & 1.35 \\
\hline *of total number of respondents. &
\end{tabular}

\section{Neglect}

Neglect refers to the unsatisfied need of a dependent older person from their caregivers. The neglect can be defined as insufficient support by caregivers providing food, shelter, transport, health care or other types of activity necessary for daily living. The 14 indicators included are listed in Table 10.

The majority of the participants did not report any need for help. Rates of neglect have been 
calculated in respect of those respondents who declared that they had been refused assistance in some type of care. Table 10 shows that $6.5 \%$ of participants experienced some type of neglect. The percentages of older woman who experienced neglect $(4.7 \%)$ is higher than the percentage of older men who experienced neglect (1.8\%).

Table 10: Neglect.

\begin{tabular}{lccc}
\hline Type of neglect & Total \% & Male \% & Female \% \\
\hline Shopping & 2.1 & 0.3 & 1.8 \\
Preparing meals & 1.7 & 0.4 & 1.3 \\
Using toilet & 0.2 & 0 & 0.2 \\
Transportation & 2.0 & 0.5 & 1.5 \\
Getting in and out of bed & 0.3 & 0.1 & 0.2 \\
Laundry & 1.4 & 0.4 & 1.0 \\
Washing & 0.4 & 0.1 & 0.3 \\
Dressing and undressing & 0.2 & 0.1 & 0.1 \\
Eating & 0.4 & 0.2 & 0.2 \\
Other household activities & 1.5 & 0.2 & 1.3 \\
General mobility in the house & 0.9 & 0.3 & 0.6 \\
Buying medications & 2.0 & 0.2 & 1.8 \\
Help with timing of medication & 1.3 & 0.2 & 1.1 \\
Getting to the doctor & 3.1 & 0.9 & 2.2 \\
Other & 0.4 & 0.2 & 0.2 \\
Overall & 6.5 & 1.8 & 4.7 \\
\hline *of total number of respondents. & & &
\end{tabular}

\section{Discussion}

Elder abuse is phenomenon which inflames interest among social and health professionals in general, but it is also important for the academic society. Finding of the prevalence of elder abuse and neglect can help further focus efforts to improve preventive and response mechanisms. To plan effectively for later life, it is important to identify expectations and assumptions about growing older [16].

There have been many surveys focused on elder abuse and neglect. One of the systematic reviews of elderly abuse for the period 1975 to 2008 [17] analysed the results of 32 such surveys. The review showed that elder abuse prevalence has been estimated in different settings; also various methods were used for data collection in these studies. A sample of various studies that depict elder abuse prevalence is presented from major epidemiological studies, agency reports, health care professionals, caregivers and family, and medical record review. Overall prevalence rates of elder abuse have varied considerably across studies, from $2.6 \%$ in the United Kingdom, $3.2 \%$ in Boston, $4 \%$ in Canada, $5.4 \%$ in Ahtari, Finland, $5.6 \%$ in Amsterdam, to $6.3 \%$ in a district of Seoul [17].

In prevalence studies on elder abuse, rates range between $1 \%$ and $35 \%$ depending on definitions in the survey and sample methods. These figures, however, may represent only the tip of the iceberg, and some experts believe that elder abuse is underreported by as much as $80 \%$. These low rates may be due to the isolation of older people, the lack of unified surveillance systems and the general resistance of people - including professionals - to report suspected cases of elder abuse and neglect [18].
In the national survey on elder abuse and neglect in Israel, overall $18.4 \%$ of respondents (men and women over 65 years) had been victims of abuse during the previous year $[19,20]$. Another Israeli study showed that $25 \%$ of elderly people were subject to neglect, which means deprivation of basic needs in various domains [21]. In the United Kingdom, the findings of a household prevalence study [22-24] for people over 65 years (in England, Scotland, Wales and Northern Ireland) showed that $2.6 \%$ of the sample had been victims of abuse. In 2000, a telephone survey in a randomly selected, community-based population in urban and rural South Australia identified that $2.7 \%$ of the older population (65 years and over) had been victims of abuse [25]. Between $4 \%$ and $10 \%$ of older Canadians each year are estimated to experience abuse of one or multiple forms [26]. The AVOW study (which included women aged between 60 and 97 years, living in private households) showed that overall $28.1 \%$ of older women had experienced some kind of abuse (Portugal (39.4\%), Belgium (32.0\%), Finland (25.1\%), Austria (23.8\%), and Lithuania (21.8\%) [27]. In a Croatian study, the data that were collected on exposure to family violence for a sample of 303 older people showed that $61.1 \%$ of elders had been exposed to at least some form of violence in the family during the previous year [28]. Findings from the current Macedonian household survey on prevalence of elder abuse and neglect, in comparison with all studies mentioned above (except for the Croatian study), showed much higher rates of overall abuse and neglect, at $32.0 \%$ for men and women 65 years and over. The differences could be the result of different definitions of elder abuse used in each study, and other methodological issues. More likely the reason for the study findings can be located in the traditional norms and beliefs in society, education, household income, health consequences, etc., [28].

Focusing on different types of abuse in the Israeli study, $18 \%$ had suffered neglect, $8 \%$ verbal abuse, $2 \%$ physical or sexual abuse, and $6.6 \%$ financial abuse $[19,20]$. The $18 \%$ who suffered neglect reported it in primary needs such as nutrition, medical services and personal hygiene (Rabi, 2006), [21]. By comparison, in our study psychological abuse was the most common form of abuse experienced $(25.7 \%)$, followed by financial abuse (12.0\%), physical abuse $5.7 \%$ and physical injury $3.1 \%$. In our study, $6.6 \%$ of the participants reported being neglected and sexual abuse was reported by $1.3 \%$ of survey participants.

The ABUEL study (EU Executive Agency for Health and Consumers, 2009) collected data on men and women aged 60 years and over in seven European Union Member States (Germany, Greece, Italy, Lithuania, Portugal, Spain, Sweden) by means of standardized assessment instruments and methods [29]. Across these countries, psychological abuse occurred more often in Sweden (29.7\%) and Germany 
$(27.1 \%)$, which is very similar to the prevalence rate in our study (25.7\%). Physical abuse occurred more often in Sweden (4\%) and Lithuania (3.8\%), similar to our findings (5.7\%). Sexual abuse occurred more often in Greece (1.5\%) and Portugal (1.3\%), similar to our findings (1.3\%). Financial abuse occurred more in Portugal (7.8\%) and Spain (4.8\%), but our findings for financial abuse (12.0\%) are higher than other countries noted. Injuries occurred more often in Lithuania (1.5\%) and Greece (1.1\%), which is lower than our prevalence rate for physical injuries (3.1\%).

In the United Kingdom household prevalence study of people aged 65 years and over, in total $2.6 \%$ reported abuse, $1.1 \%$ experienced neglect, $0.7 \%$ financial abuse, $0.4 \%$ psychological abuse, $0.4 \%$ physical abuse and $0.2 \%$ sexual abuse [22-24]. The prevalence of abuse was higher among women $(3.8 \%)$ than among men $(1.1 \%)$, as is the case in our study (19.4\% among women and $12.6 \%$ among men), but the different types of abuse and neglect are much higher in our study.

In Australia, $2.7 \%$ of the older population (65 years or older) reported being abused. The most common form of abuse reported was psychological, with financial being the next most common, followed by physical abuse and neglect [25]. This confirms the findings of our study, where psychological abuse is the most frequent type of abuse, followed by financial abuse.

A national survey on elder abuse in Canada found that financial abuse was most commonly reported $(2.5 \%)$, followed by chronic verbal aggression $(1.4 \%)$, physical violence $(0.5 \%)$, and neglect $(0.4 \%)[26,30,31]$. In our study the financial abuse is the second hires prevalence rate similar to the Canadian study.

In the AVOW study, emotional abuse was the most common form of abuse experienced (23.6\%), followed by financial abuse $(8.8 \%)$, violation of rights $(6.4 \%)$ and neglect (5.4\%). Sexual abuse (3.1\%) and physical violence $(2.5 \%)$ were the least reported forms [27]. There has been similarity with our study findings as the results of the AVOW study: psychological abuse $(25.7 \%)$, followed by financial abuse $(12.0 \%)$, physical abuse $5.7 \%$ and physical injuries $3.1 \%$, and $6.6 \%$ for neglect. Overall levels of sexual abuse are lower in the Macedonian study (1.3\%), reported only by women, than in any country included in the AVOW study (the lowest percentage reported was in Austria, 2.1 [27].

Similarities have been found with our study and a Hong Kong study with regard to psychological abuse, $25.7 \%$ compared with $20.8 \%$ [31]. In the Russian Federation study, $24.4 \%$ of women and $4.2 \%$ of men were found to have experienced some form of abuse [32].

In the Macedonian survey, only $22.7 \%$ of victims have reported to the services the abuse or neglect and $77.3 \%$ did not. Similar data have been found in a United States study, where $21 \%$ of abuse was reported to Adult Protective Services (APS) agencies, with the remaining $79 \%$ not being reported $[33,34]$. It can be concluded from these figures that almost four times as many new incidents of elder abuse, neglect and/or self-neglect were unreported than were reported [33, 34].

The overall prevalence rate and prevalence rate obtained for different types of abuse (and neglect) are higher than prevalence rates of abuse obtained in other countries, except in the Croatian study (which is a country from the same region as our country). The differences in prevalence rates might result from differences in definition of the problem for research, the methodology and statistical tests used. In a developing country such as our country, it could be hypothesized that older people may have been more exposed to different types of abuse and neglect partly owing to poverty and its social effects. We could also stress that in many cases the elder is the only breadwinner in the family, bearing in mind the very high rate of unemployment in the country (around $31 \%$ ), which could be a potential risk factor for being abused and neglected [12].

We could conclude that defining the phenomenon of elder abuse and neglect in the context of our country can facilitate support of abused older people and, most importantly, may help develop policy and programmes targeting prevention and response. Coordination between scientists and practitioners can improve decision-making in prevention and response to elder abuse and neglect. Highly indispensable task is strengthening response and support for victims of elder abuse and neglect through extensions of the role of health, social and other relevant sectors in secondary and tertiary prevention of elder abuse and neglect together with the improvement of the quality of health care, and piloting and implementing services based on evidence-based practices. More emphasis should be given to the integration of prevention of elder abuse and neglect into social and education policy based on human rights approach and promotion of gender and social equality of older people through various prevention programmes and educational campaigns.

\section{Acknowledgment}

The data used in this article is an integral part of the data collected for more comprehensive project "A Community survey in Macedonia of the prevalence of elderly abuse" that will be published. The study has been conducted during the period from December 2011 to February 2012. Implementation of the study was enabled with technical and financial support by the World Health Organization in collaboration with the Institute of Sociological, Political and Juridical Research in Skopje. 


\section{References}

1. Burston RG. Granny-battering. BMJ. 1975:592.

2. World Health Organization. Forty-ninth World Health Assembly Resolution, WHA49.25 Prevention of violence: a public health priority. Geneva: WHO,1996.

3. Krug EG, Dahlberg LL, Mercy JA, Zwi AB, Lozano R, et al. eds. World report on violence and health. Geneva: World Health Organization, 2002.

4. Butchart A, Phinney A, Check P, Villaveces A. Preventing violence: a guide to implementing the recommendations of the World report on violence and health. Geneva: Department of Injuries and Violence Prevention, World Health Organization, 2004.

5. Sethi D, Wood S, Mitis F, et al., eds. European report on preventing elder maltreatment. Copenhagen: WHO Regional Office for Europe, 2011.

6. World Health Organization. Social development and ageing Crisis or opportunity? Special panel at Geneva 2000. Geneva: WHO, 2000

7. WHO. Definition of older or elderly person http://www.who.int/healthinfo/survey/ageingdefnolder/en/. Assessed February 7, 2014.

8. WHO/INPEA. Missing voices. Geneva:World Health Organisation; 2002. http://whqlibdoc.who.int/hq/2002/WHO_NMH_VIP_02.1.pdf. Accessed December 12, 2011

9. National Committee for the prevention of elder abuse/MetLife Mature Market Institute. The essentials: Preventing elderly abuse. New York: NY, 2011.

10. Tozija F,Gjorgev D, Chichevalieva S. Report on violence and health in Macedonia and guide for prevention. Skopje: Ministry of Health, 2006.

11. Ministry of Labour and Social Policy. Annual report 2010. Skopje: Ministry of Labour and Social Policy, 2010.

12. State Statistical Office. Estimation of population on 30.06.2010 and 31.12.2010 according to the gender by municipality and statistical regions. Skopje: State Statistical Office, Republic of Macedonia, 2011. http://nww.stat.gov.mk/publikacii/2.4.11.14.pdf. Accessed November 20, 2011

13. Karolinska Institute. ABUEL, Abuse of elderly in Europe. Stockholm: Karolinska Institute; 2009. http://www.abuel.org/project.html. Accessed October 9, 2011.

14. National Institute for Health and Welfare THL. Prevalence study of violence and abuse against older women (AVOW). Helsinki: National Institute for Health and Welfare THL; 2010. http://www.thl.fi/avow. Accessed October 9, 2011.

15. Krsteska R. Mini Mental Test kaj Alchajmerova i vaskularna demencija. [Mini Mental Test in Alzheimer's and vascular dementia.]. Makedonski Medicinski Pregled [Macedonian Medical Review]. Skopje: University "Ss Cyril and Methodius", 2007.

16. APA Committee on Aging. Life plan for the life span. Washington DC: APA; 2005. www.apa.org/pi/aging/lifespan2008.pdf. Accessed September 15, 2012

17. Daly JM, Merchant ML, Jogerst GJ. Elder Abuse Research: A Systematic Review, Journal of Elder Abuse \& Neglect. 2011; 23:4, 348-65. doi:10.1080/08946566.2011.608048.

18. World Health Organization. The global response to elder abuse and neglect: building primary health care capacity to deal with the problem worldwide: main report. Geneva: WHO, 2008.

19. Lowenstein A, Eisikovits Z, Band-Winterstein T, Enosh G. Is elder abuse and neglect a social phenomenon? Data from the First National Prevalence Survey in Israel. J Elder Abuse
Neglect. 2009;21:253-77.

20. Eisikovits $Z$, Winterstein $T$, Lowenstein $A$. The national survey on elder abuse and neglect in Israel. The Center for Research and Study on Ageing (National Insurance Institute), 2004.

21. Rabi K. Israeli perspectives on elder abuse. Educ Gerontol. 2006;32:49-62.

22. O'Keeffe M, Hills A, Doyle M, et al. UK study of abuse and neglect of older people. Prevalence study. King's College London and National Centre for Social Research. London, 2007.

23. Daskalopoulos M, Mullin ASJ, Donovan E, Suzuki H. English perceptions of elder abuse. Journal of Elder Abuse \& Neglect. 2006;18(2-3):33-50.

24. Biggs S, Manthorpe J, Tinker A, Doyle M, Erens B. Mistreatment of Older People in the United Kingdom: Findings from the First National Prevalence Study. Journal of Elder Abuse \& Neglect. 2009;21(1):1-14.

25. Kurrle S, Naughtin G. An overview of elder abuse and neglect in Australia. Journal of Elder Abuse \& Neglect. 2008; 20(2):108-25.

26. Wilson DM, Ratajewicz SE, Els C, Asirifi MA. Evidence-based approaches to remedy and also to prevent abuse of community-dwelling older persons. Nurs Res Pract. 2011; 861484. doi: $10.1155 / 2011 / 861484$

27. Luoma M-L, Koivusilta M, Lang G, et al. Prevalence Study of Abuse and Violence against Older Women. Results of a Multicultural Survey in Austria, Belgium, Finland, Lithuania, and Portugal (European Report of the AVOW Project). Finland: National Institute for Health and Welfare (THL), 2011.

28. Ajdukovic M, Rusac S, Ogresta J. Izlozenost starijih osoba nasilju u obitelji [Exposure of elderly to family violence]. Revija za socijalnu politiku [Journal of Social Policy]. 2008;15(1):322.

29. Soares JJF, Barros H, Torres-Gonzales F, et al. Abuse and health in Europe. Kaunas: Lithuanian University of Health Sciences Press, 2010

30. Walsh CA, Yon Y. Developing an empirical profile for elder abuse research in Canada. Journal of Elder Abuse \& Neglect. 2012;24 (2):104-119.

31. Yan E, Tang CSK. Prevalence and psychological impact of Chinese elder abuse. Journal of Interpersonal Violence. 2001;16(11):1158-74.

32. Vasilvevich P. Elder abuse: current research in the Russian Federation (2004-2006). Journal of Adult Protection. 2006;8(4):4-12.

33. National Center on Elder Abuse at the American Public Human Services Association. The National Elder Abuse Incidence Study. Final Report. Washington, DC, National Center on Elder Abuse at the American Public Human Services Association, Westat Inc., 1998.

34. Tatara, T. Toward development of estimates of the national incidence of elder abuse based on currently available data: an exploratory study. In: Filison RR, Ingman SR, eds. Elder abuse: practice and policy. New York: Human Sciences Press, 1989:153-65. 